\title{
The Influence of Cr Addition and Heat Treatment on Dilatometric Characteris- tics of Cast Fe-Al-Si Intermetallic Alloys
}

Věra Vodičková (0000-0001-7100-9932)1, Petra Pazourková Prokopčáková (0000-0002-9434-6349)², Martin Švec (0000-0003-3198-3356)3, Pavel Hanus (0000-0003-1533-1016)4, Jaromír Moravec (0000-0003-4731-5969)5, Libor Camek (0000-0002-2835-2054) ${ }^{6}$

${ }^{1}$ Faculty of Mechanical Engineering, Technical University of Liberec. Studentská 1402/2, Liberec. Czech Republic. E-mail: vera.vodickova@tul.cz

${ }^{2}$ Faculty of Mechanical Engineering, Technical University of Liberec. Studentská 1402/2, Liberec. Czech Republic. E-mail: petra.prokopcakova@tul.cz

${ }^{3}$ Faculty of Mechanical Engineering, Technical University of Liberec. Studentská 1402/2, Liberec. Czech Republic. E-mail: martin.svec@tul.cz

${ }^{4}$ Faculty of Mechanical Engineering, Technical University of Liberec. Studentská 1402/2, Liberec. Czech Republic. E-mail: pavel.hanus@tul.cz

${ }^{5}$ Faculty of Mechanical Engineering, Technical University of Liberec. Studentská 1402/2, Liberec. Czech Republic. E-mail: jaromir.moravec@tul.cz

${ }^{6}$ Department of Foundry Engineering, Brno University of Technology. Technická 2896/2, Brno. Czech Republic. E-mail: camek@fme.vutbr.cz@tul.cz

The cast Fe-Al-Si type intermetallic alloys (with or without chromium content) were investigated with the aim to obtain the values of thermal expansion coefficient and describe the dilatometric behavior of alloys. The effect of chromium addition, as well as the influence of heat treatment on the structure and dilatometric characteristics (thermal expansion coefficient, CTE), were described.

It has been shown that the presence of chromium does not significantly influence the values of thermal expansion coefficient of as-cast alloys so that chromium addition can be substituted by higher silicon content. The annealing used for phase stabilization slightly decreases the CTE values for chromium doped alloys, nevertheless only in the higher temperature range. In comparison, CTE values of the alloy without chromium are slightly increased by the annealing used in the whole temperature interval. But, the differences are not significant from the point of view of technical practice.

Keywords: $\mathrm{Fe}_{3} \mathrm{Al}$-type iron aluminides, silicon and chromium addition, thermal expansion coefficient, heat-treatment

\section{Introduction}

The greatest advantages of intermetallic alloys based on $\mathrm{Fe}-\mathrm{Al}$ include, above all, excellent resistance to oxidation and sulfidation even at high temperatures. Their corrosion properties are significantly better than traditional iron alloys highly alloyed with chromium (e.g. Fe-25Cr-20Ni or Fe-18Cr-6Al). Another advantage is the lower specific gravity than other iron alloys, such as cast irons or stainless steels, which gives these materials the potential for use in transport applications (parts of vehicles). Last but not least, excellent wear resistance (for $\mathrm{Fe}_{3} \mathrm{Al}$-based alloys comparable to the resistance of AISI 1016 or SUS304 steels) as well as high electrical resistivity [1], [2].

An obstacle to the wider use of these materials is, in particular, their brittleness and low ductility at room temperature, as well as a sharp drop in strength above $600{ }^{\circ} \mathrm{C}$ [1]. The ductility of these alloys at higher tem- peratures, on the other hand, is very good and can therefore be machined with conventional hot technologies [2].

Thanks to the properties and advantages mentioned above (and despite the described disadvantages), intermetallic alloys based on $\mathrm{Fe}-\mathrm{Al}$ have to date found, among other things, for example for resistance heating elements, furnace components, parts of valve systems, exhaust pipes, heat exchangers in turbine systems, catalyst substrates, metal sintered filters for coal gasification, holders for heat treatment in carburizing environment, components in petrochemical industry and applications in a molten salt environment [2]. Mechanical properties, in particular strength, ductility and wear resistance, weldability, and chemical resistance, can be influenced to a large extent by the addition of alloying elements and the control of the microstructure $[1,3]$.

Chromium has been found to improve the tensile ductility of iron aluminides at room temperature [3, 4]. 
Also, the effect of chromium on the high-temperature yield stress of $\mathrm{Fe}_{3} \mathrm{Al}$-based iron aluminides was mentioned $[5,6]$. Chromium strengths $\mathrm{Fe}_{3} \mathrm{Al}$ matrix through the solid solution hardening; nevertheless, the strengthening effect decreases with increasing temperature [6]. One of the elements whose influence on the structure and properties of iron aluminides is still in the research phase is silicon. It has been found [1] that the addition of silicon increases the strength of these alloys at high temperatures, the creep resistance at high temperatures, and also the oxidation resistance. In the research of the FeAl-based alloy called Pyroferal, the influence of silicon on the formation of a composite-type structure, which is associated with excellent high-temperature mechanical properties of this alloy, was demonstrated [7-9].

Recently, the group of $\mathrm{Fe}-\mathrm{Al}-\mathrm{Si}$ intermetallic alloys prepared by powder metallurgy, especially by mechanical alloying, was investigated from different points of view - the effect of silicon on the structure, mechanical properties or, high-temperature behaviour was tested [10-12]. Further research [13,14] reports a significant effect of silicon on the oxidation resistance of $\mathrm{Fe}-\mathrm{Al}$ based alloys by improving the protective effect of the oxide layer on the surface of the material and the formation of other oxidation-resistant silicon-rich phases below this layer.

As mentioned above, iron aluminides are considered to be materials suitable for high-temperature applications. So the knowledge of their behaviour at high temperatures is necessary because thermal stability together with the high-temperature strength limits the use of these materials.

The dilatometric analysis is based on the fact that the phase changes in the material structure are usually accompanied by material volume changes corresponding to the change in length [15]. If the course of changes in the examined material size is recorded during its heating or cooling (i.e. depending on the temperature), a dilatation curve can be obtained. From the resulting dilatation curve, the phase transformation temperatures of a given material or the kinetics of phase transformations of metals and their alloys can be determined.

From the results of dilatometric measurements, it is possible to determine the coefficients of linear longitudinal thermal expansion (CTE Coefficient of Thermal Expansion) $\left[\mathrm{K}^{-1}\right]$, an important physical property of each material. The value of the coefficient of longitudinal thermal expansion CTE is calculated from the relation (1) where $l_{0}[\mathrm{~mm}]$ is the length of the sample at the initial temperature $\mathrm{T}_{0}\left[{ }^{\circ} \mathrm{C}\right]$ and $\mathrm{l}_{\mathrm{T}}[\mathrm{mm}]$ is the length of the sample at the temperature $\mathrm{T}\left[{ }^{\circ} \mathrm{C}\right]$ [15].

$$
C T E=\frac{l_{T}-l_{0}}{T-T_{0}} \cdot \frac{1}{l_{0}}\left[K^{-1}\right],
$$

Based on the knowledge of CTE curves of materials, the behaviour of parts can be predicted, among other things in construction at elevated temperatures (dimensional stability), dimensional change during phase transformations in the material or to estimate the behaviour of the material during high-temperature mechanical tests (change of mechanical properties due to change of structure).

Regarding dilatometric characteristics of iron aluminides, there are not many sources of information. The comparison of FeAl-based to $\mathrm{Fe}_{3} \mathrm{Al}$-based aluminides, with different additive elements or their combination, was given [16]. It was proven that $\mathrm{Fe}_{3} \mathrm{Al}$-based alloys show lower values of CTE than FeAl-based alloys. Vanadium also proved to be the most suitable additive for $\mathrm{Fe}_{3} \mathrm{Al}$-based alloys, the values of CTE were comparable with AKC steel. Afterwards, the effect of different additives on the thermal expansion of $\mathrm{Fe}_{3} \mathrm{Al}-$ based iron aluminides was investigated in detail [1719]. The CTE values of alloys doped with zirconium, niobium, or carbon, were connected with different types of structure, i.e. with different phase composition and/or phase distribution.

This article aims at the dilatometric data accumulation of FeAlSi intermetallic alloys prepared by the "classic" casting process and evaluation of the heat treatment effect on dilatometric characteristics of investigated alloys.

\section{Materials and methods}

The investigated alloys were prepared at VŠB-TU Ostrava. The starting raw materials for their preparation were Fe - AREMA (max. 0.05 wt. \% C), Al with a purity of $99.995 \%$, Si with a purity of $99.9 \%$, and $\mathrm{Cr}$ with a purity of $99.9 \%$. The alloys were melted in a vacuum furnace at an absolute pressure of less than 6 $\mathrm{Pa}$. The chemical compositions of the prepared alloys and their subsequent marking are given in Table 1.

Tab. 1 Chemical composition and marking of investigated alloys

\begin{tabular}{|c|c|c|c|c|c|c|c|}
\hline & \multicolumn{7}{|c|}{ The nominal chemical composition [at. \%] } \\
\hline & \multicolumn{2}{|c|}{$\mathrm{Al}$} & \multicolumn{2}{|c|}{$\mathrm{Si}$} & \multicolumn{2}{|c|}{$\mathrm{Cr}$} & \multirow{2}{*}{$\frac{\mathrm{Fe}}{\text { [at. } \%}$} \\
\hline & [at. \%] & [hm. \%] & [at. \%] & [hm. \%] & [at. \%] & [hm. \%] & \\
\hline FA5Si3Cr & 28 & 16.74 & 5 & 3.11 & 3.5 & 4.03 & bal. \\
\hline FA10Si3Cr & 28 & 16.84 & 10 & 6.26 & 3.5 & 4.05 & bal. \\
\hline FA10Si & 28 & 16.79 & 10 & 6.24 & - & - & bal. \\
\hline
\end{tabular}


For structure analysis, two metallographic samples were prepared from each alloy - for the as-cast state and the state after long-term annealing at $1000{ }^{\circ} \mathrm{C}$ for $100 \mathrm{~h}$.

The samples of all materials were oxide-polished. For the structure preview, a light optical microscope Nicon was used (LOM). The microstructure was examined in detail by scanning electron microscope (SEM) Zeiss Ultra Plus supplemented with Oxford detector for energy-dispersive $\mathrm{X}$-ray analysis (EDX).

Dilatometric measurements to determine the CTE coefficients of the investigated alloys were performed on a DIL805L dilatometer. It is a horizontal dilatometer with a closed measuring chamber allowing measurements in various environments, such as air, vacuum, or inert gas. The sample is heated by an induction coil. The sensitivity of the dilatometer is 0.05 $\mu \mathrm{m}$ for length measurements and $0.05{ }^{\circ} \mathrm{C}$ for temperature measurements. Measurements of sample length changes are performed using an LVDT sensor. Temperature measurement is provided by a thermocouple welded to the sample.

For dilatometric measurements, the cylindrical samples with a diameter of $4 \mathrm{~mm}$ and a length of 10 $\mathrm{mm}$ were prepared by electro-discharge machining (EDM). Samples of three investigated alloys were prepared for conditions after casting and after long-term annealing at $1000^{\circ} \mathrm{C}$ for $100 \mathrm{~h}$. The thermal expansion measurement of the investigated alloys took place in a vacuum, with a heating rate of $1{ }^{\circ} \mathrm{C} / \mathrm{s}$ to a temperature of $950^{\circ} \mathrm{C}$. An S-type thermocouple (Pt / Rh-Pt) was used to measure the temperature. The test specimen is placed in the measuring chamber of a dilatometer with a welded thermocouple and a heating induction coil.

\section{Structure and dilatometric tests of as-cast alloys}

Before dilatometry tests, structures of tested alloys were studied to better understanding dilatometric behaviour. The structure analysis of two of these alloys was performed previously in [20].

No particles of any secondary phase were observed (Fig. 1,2) in the structure of as-cast alloy FA5Si3Cr. Considering EDX analyses, all chromium was dissolved in the matrix.

Due to chromium addition and carbon content (from Arema coming), more types of secondary particles were observed in the structure of FA10Si3Cr alloy in the as-cast state [20]. Two types of particles differing in chromium content were described inside the grains, and also eutectic-like areas composed of matrix and chromium (or iron-chromium) carbide [20].
In the as-cast structure of the "pure" ternary FAl10Si alloy, very tiny carbide particles (thickness about $10-20 \mathrm{~nm}$ ) were observed along grain boundaries [20]. By EDX analyses, these particles were preliminarily identified as perovskite-type particles. Inside the grains, very small-sized needle-like particles (under EDX resolution) were also found evenly distributed in the matrix [20]. They can be supposed to be also perovskite carbides.

From the measured data, there were calculated the respective values of the CTE coefficient depending on the temperature for each alloy at all states according to formula (1). A graph in Fig. 3 shows a mutual comparison of the CTE curves of individual alloys in the state after casting.

The CTE curves of FA5Si3Cr alloy and FA10Si alloy have a similar course up to a temperature of about $920^{\circ} \mathrm{C}$, but the $\mathrm{FA} 5 \mathrm{Si3} \mathrm{Cr}$ alloy curve is equidistantly shifted by about $1 \cdot 10-6 \mathrm{~K}-1$ above (Fig. 3).

The CTE curve course of alloy FA10Si3Cr is practically identical to the course of the FA10Si alloy curve up to a temperature of about $380{ }^{\circ} \mathrm{C}$ (Fig. 3). The changes in the slope of the curve corresponding (with high credibility) to the recrystallization temperatures are possible to watch on the curve of alloy FA10Si3Cr. There is a nonlinear increase of its slope and a more significant change at a temperature of about $520^{\circ} \mathrm{C}$. This more pronounced change in slope is probably related to the phase transformation of the ordered structure D03 to B2, which is in good agreement with the binary diagram $\mathrm{Fe}-\mathrm{Al}$ (app. $550{ }^{\circ} \mathrm{C}$ ) if the effect of additives is taken into account. Another significant change in the curve slope can only be estimated in the region of about $920{ }^{\circ} \mathrm{C}$. Here, the ordered structure B2 to disordered A2 can be assumed, following the binary diagram $\mathrm{Fe}-\mathrm{Al}$ and also, the results given in [19] where the influence of different additives on phase transformation temperatures for $\mathrm{Fe} 3 \mathrm{Al}$ based iron aluminides was determined.

On the CTE curve of alloy FA5Si3Cr (Fig. 3), only the first slope change is recordable around the temperature of $520{ }^{\circ} \mathrm{C}$, similar to $\mathrm{FA} 10 \mathrm{Si3Cr}$ alloy. For FA5Si3Cr alloy within the whole measured temperature range, the smallest variability of the CTE coefficient from the compared alloys is then shown. The size of the interval between temperatures of 200 and $950{ }^{\circ} \mathrm{C}$ is app. $6.5 \cdot 10-6 \mathrm{~K}-1$ for FA5Si3 Cr alloy.

The changes in the slope are not easily recognizable in the case of alloy FA10Si (Fig. 3). Therefore, the recrystallization temperatures cannot be even determined from them. Of the investigated alloys, this alloy shows the most uniform (almost linear) increase in the values of the CTE coefficient in the entire measured temperature range. 


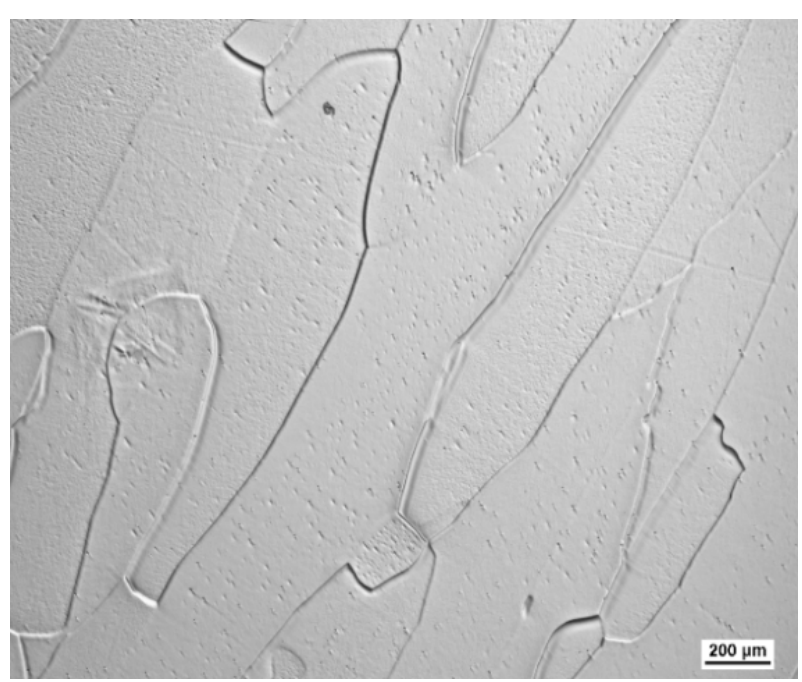

Fig. 1 Preview of as-cast F A5Si3Cr alloy structure, LOM

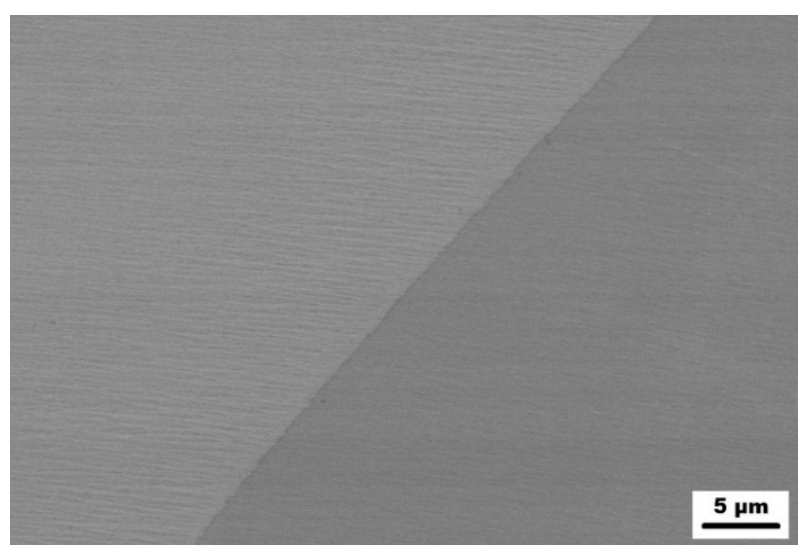

Fig. 2 As-cast FA5Si3Cr alloy, detail of grain boundaries, SEM

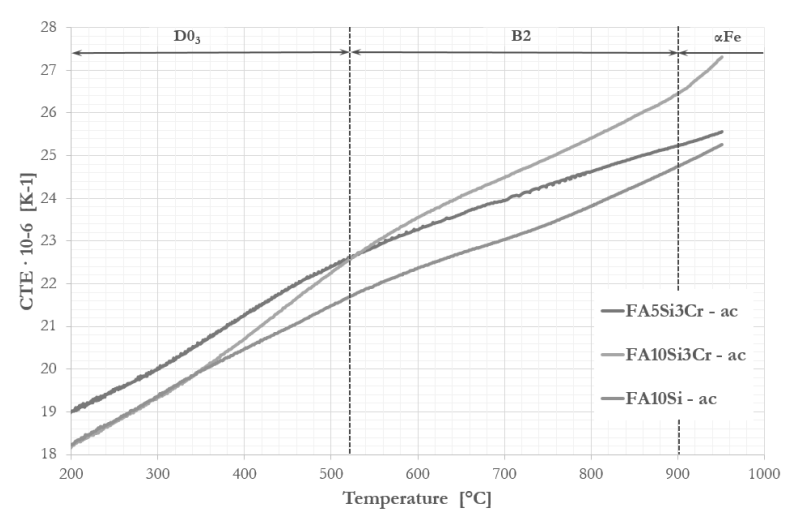

Fig. 3 Dependence of CTE values on temperature for alloys FA5Si3Cr, FA10Si3Cr, FA10Si in the as-cast (ac in the description) state

\section{Structure and dilatometric tests of anne- aled alloys}

The annealing at $1000{ }^{\circ} \mathrm{C}$ for 100 hours had no significant effect on the FA5Si3Cr alloy structure - Fig 4, 5 . No secondary phase particles were found at or near the grain boundaries.

In the structure of FA10Si3Cr alloy annealed at $1000{ }^{\circ} \mathrm{C}$ for 100 hours, the coarsening of the particles (identified by EBSD as complex carbide $\mathrm{Cr}_{19} \mathrm{Fe}_{4} \mathrm{C}_{6}$ ) along grain boundaries was noticed. On the other hand, the eutectic-like areas were completely dissolved, while the individual particles inside of grains were partially dissolved [20].

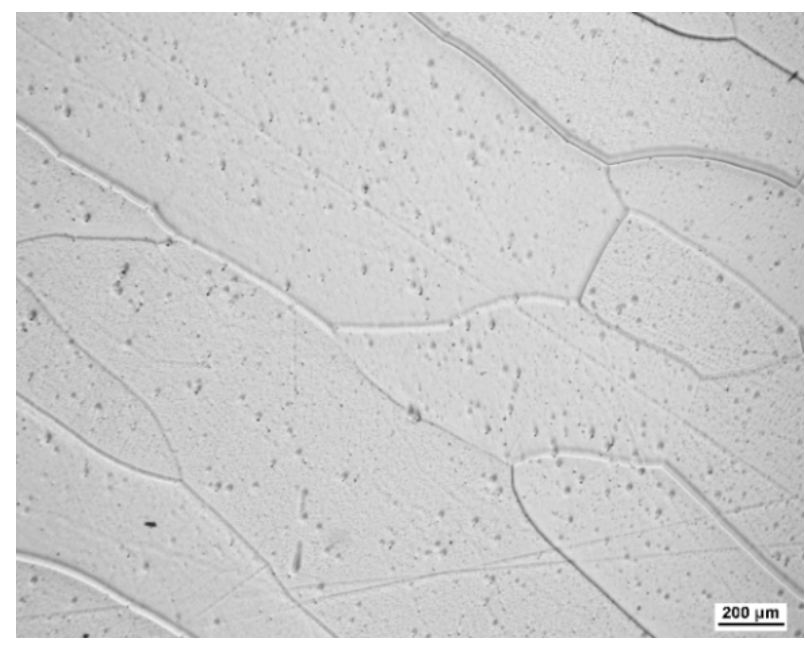

Fig. 4 Preview of annealed FA5Si3 Cr alloy structure, LOM

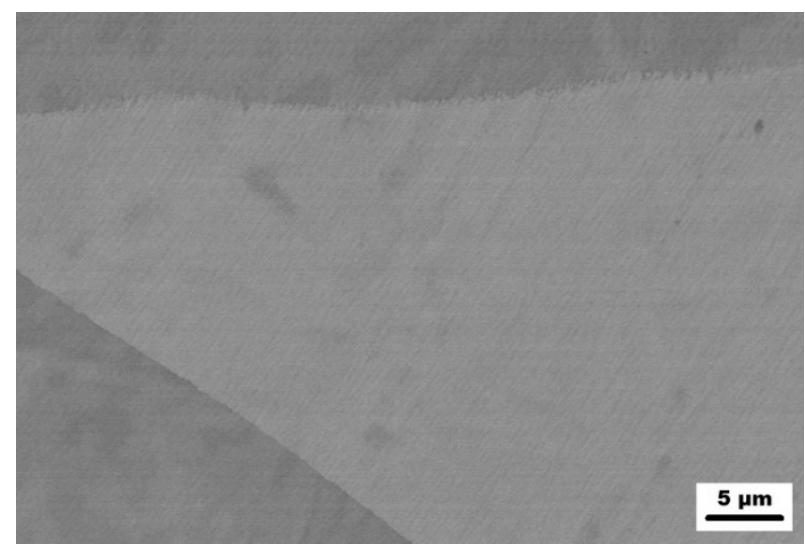

Fig. 5 Annealed FA5Si3Cr alloy, detail of grain boundaries, SEM

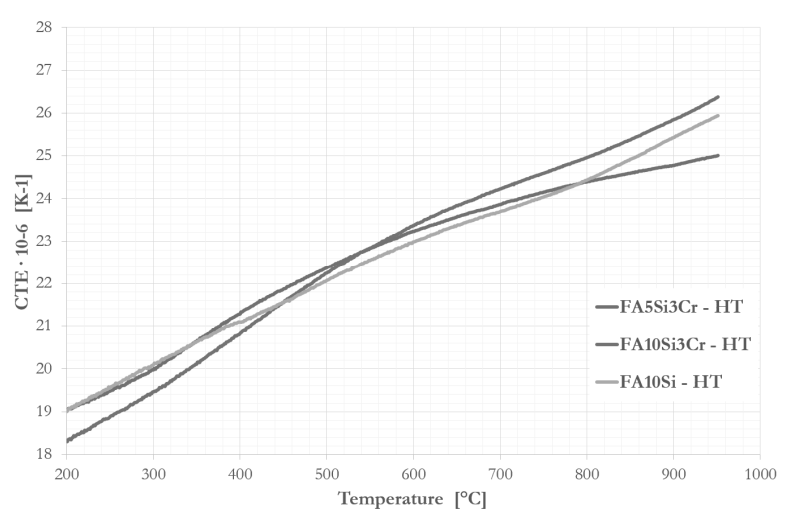

Fig. 6 Dependence of CTE values on temperature for alloys FA5Si3Cr, FA10Si3Cr, FA10Si, in the state after longterm annealing at $1000{ }^{\circ} \mathrm{C}$ for $100 \mathrm{~b}$ (HT in the description) 
Long-time annealing at $1000{ }^{\circ} \mathrm{C}$ affects the structure of ternary alloy FA10Si significantly - the particles of the secondary phase were completely dissolved [20].

The respective values of the CTE coefficient depending on the temperature for each alloy in the annealed state were calculated according to formula (1). A CTE curves mutual comparison of individual annealed alloys is given in Fig. 6. After long-term annealing, all CTE curves appear without significant slope changes, so the determination of phase transformation temperatures is not entirely relevant. The CTE curves of alloys FA5Si3Cr and FA10Si have an almost identical course, up to a temperature of approximately 820 ${ }^{\circ} \mathrm{C}$. This course is no longer equidistant, as was the case in the above-described as-cast state.

The CTE curve of FA10Si3Cr (Fig. 6) alloy does not show as significant changes in slope after longterm annealing as it did after casting. It can be stated that it has a similar course as the curves of alloys FA5Si3Cr and FA10Si, up to higher temperatures. The CTE values of all tested alloys are almost identical in the temperature range of $400-640{ }^{\circ} \mathrm{C}$. Nevertheless, FA10Si3Cr alloy shows not such a steady increase of CTE values (compared to alloys FA5Si3Cr and FA10Si) - these values are the lowest up to $400{ }^{\circ} \mathrm{C}$ while they are the highest at higher temperatures, above $640^{\circ} \mathrm{C}$.

On the contrary, FA5Si3Cr alloy shows the lowest variability of the CTE coefficient in the measured temperature range even after long-term annealing. Above $800{ }^{\circ} \mathrm{C}$, the CTE values of this alloy are also the lowest. The difference between the values of the CTE coefficient in the interval between 200 and $950{ }^{\circ} \mathrm{C}$ is less than $6 \cdot 10^{-6} \mathrm{~K}^{-1}$.

The CTE curve of FA10Si alloy again shows a more uneven growth of the compared alloys in the whole measured temperature interval (Fig. 6).

\section{The effect of heat treatment on dilatomet- ric characteristics}

To stabilize their structure, long-term heat treatment - annealing at $1000{ }^{\circ} \mathrm{C}$ for $100 \mathrm{~h}$ was applied for investigated alloys. CTE values were calculated coefficients for the temperature range of 200 to $950{ }^{\circ} \mathrm{C}$. Graphs (CTE curves, Figs 7, 8) of the dependence of CTE coefficients were created from the calculated values for mutual comparison and possible detection of recrystallization temperatures. From Figs 7 and 8, it can be concluded that long-term annealing $100 \mathrm{~h} /$ $1000^{\circ} \mathrm{C}$ does not significantly affect the values of CTE coefficients of FA5Si3Cr alloy and FA10Si3Cr alloy, especially in the temperature range $200-600^{\circ} \mathrm{C}$. The CTE curves of alloys in as-cast and annealed states have a practically identical or very close course up to a temperature of about $760{ }^{\circ} \mathrm{C}$ for FA5Si3Cr alloy, or, respectively, $700{ }^{\circ} \mathrm{C}$ for FA10Si3Cr alloy. In the range of higher temperatures, there is a slight decrease in CTE values for both alloys in the annealed state compared to the as-cast state. In the case of FA10Si3Cr alloy, this slight decrease of CTE coefficients (by about $0.5 \cdot 10^{-6} \mathrm{~K}^{-1}$ ) could be related to the above-mentioned partial dissolution of eutectics-like secondary phase particles along grain boundaries at higher temperatures. The partial dissolution of the secondary phase can lead to the enrichment of solid solution in the matrix by chromium and carbon and, also, to the coarsening of chromium carbide particles [20]. Due to this process, the total length of interphase boundaries changes and can influence the CTE values.

Of the investigated alloys, alloy FA10Si shows the almost linear increase in the values of CTE coefficients in the entire measured temperature interval Fig. 9.

In contrast with CTE curves of alloys FA5Si3Cr and FA10Si3Cr in annealed states, the CTE curve of the long-term annealed alloy FA10Si shows an equidistant increase (up to $950^{\circ} \mathrm{C}$ ) in the values of the CTE coefficients by approximately $1 \cdot 10^{-6} \mathrm{~K}^{-1} \mathrm{com}-$ pared to the CTE curve of FA10Si alloy in the as-cast state - Fig. 9. This equidistant displacement can be caused by the dissolution of very tiny carbide particles due to long-term annealing. This dispersion of the fine particles could strengthen the matrix of FA10Si alloy in the as-cast state in a similar way as dispersion strengthening of composite material is working. After the dissolution of these fine carbides due to annealing, CTE values have increased.

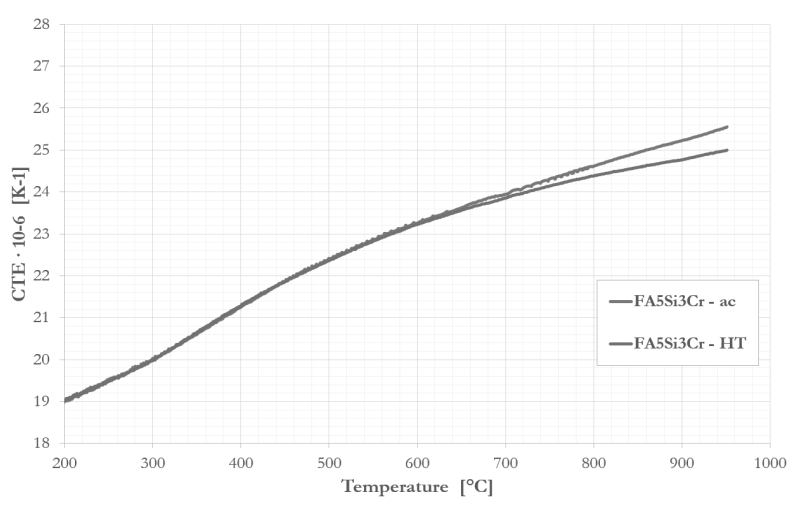

Fig. 7 Effect of annealing on CTE values of $\mathrm{FA} \mathrm{AS}$ i3 Cr alloy

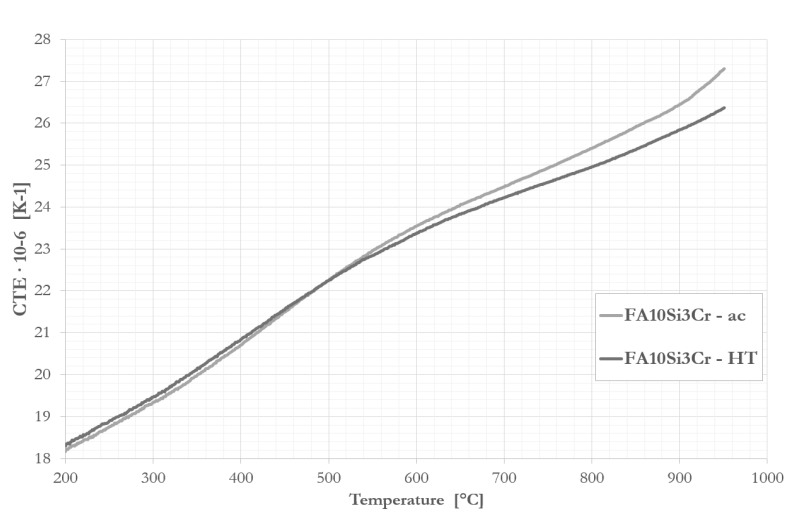

Fig. 8 Effect of annealing on CTE values of FA1OSi3Cr alloy 


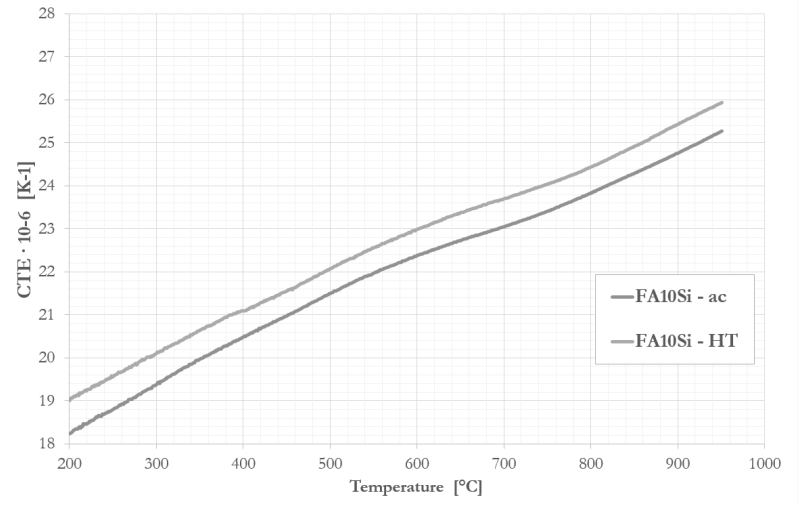

Fig. 9 Effect of annealing on CTE values of alloy FA10Si

\section{Conclusion}

There were no significant differences between the range of CTE values of investigated alloys with or without chromium addition. The bigger differences - in order $2.10^{-6}$ - were recorded at higher temperatures (app. from $800^{\circ} \mathrm{C}$ ). Concerning the expected interval of use of alloys up to $600{ }^{\circ} \mathrm{C}$, these differences appear to be not essential. In this case, the chromium (as an element that belongs to Critical Raw Materials) can be substituted by silicon content, ideally between 5-10 at. $\%$. Silicon content higher than 10 at. \% can be useful for CTE as well for high-temperature mechanical properties (especially up to $600{ }^{\circ} \mathrm{C}$ ) as reported in [21] for Fe-28Al-15Si-2Mo alloy. However, the material processing (cutting, rolling) significantly deteriorates with silicon content increasing.

Regarding the phase composition, it is necessary to notice that using very pure input raw materials would prevent the chromium carbide formation in alloy FA10Si3Cr, then the CTE values of this alloy could be more favourable.

The annealing used for phase stabilization slightly reduces the CTE values for $\mathrm{FA} 5 \mathrm{Si3} \mathrm{Cr}$ and $\mathrm{FA} 10 \mathrm{Si3} \mathrm{Cr}$ alloys in the temperature range app. $700-950{ }^{\circ} \mathrm{C}$ (FA5Si3Cr) or $500-950{ }^{\circ} \mathrm{C}$ (FA10Si3Cr), probably due to the enrichment of solid solution in the matrix by chromium and carbon during the partial dissolution of eutectics-like phase. On the contrary, for FA10Si alloy CTE values are slightly increased by the annealing used in the whole temperature interval. This almost equidistant increase in CTE values can be caused by the dissolution of very tiny carbide particles (reinforcing the matrix in the as-cast state) due to longterm annealing.

\section{Acknowledgement}

This work was supported by the Ministry of Education, Youth and Sports of the Czech Republic and the European Union - European Structural and Investment Funds in the frames of Operational Programme Research, Development and
Education - project Hybrid Materials for Hierarchical Structures (HyHi, Reg. No. CZ.02.1.01/0.0/0.0/16_019/0000843).

\section{References}

[1] MC KAMEY, C. G. (1996). Physical Metallurgy and Processing of Intermetallic Compounds, pp. 351 391. Chapman \& Hall Publisher, New York. ISBN 978-0-412-98971-1

[2] STOLOFF, N. S. (1998). Iron aluminides: present status and future prospects. In: Materials Science and Engineering, Vol. A258, No. 1, pp. 1 14

[3] DEEVI, S. C., SIKKA, V. K. (1996). Nickel and iron aluminides: an overview on properties, processing and applications. In: Intermetallics, Vol. 4, pp. $357-375$

[4] SAUTHOFF, G. (1995). Intermetallics, pp. 84 89. VCH Publisher, Weinheim. ISBN 3-52729320-5

[5] MC KAMEY, C. G., HORTON, J. A., LIU, C. T. (1989). Effect of chromium on properties of Fe3Al. In: Journal of Materials Research, Vol. 4 No. 5, pp. 1156

[6] PALM, M. (2005). Concepts derived from phase diagram studies for the strengthening of Fe-Al - based alloys. In: Intermetallics, Vol. 13, pp. $1286-1295$

[7] KRATOCHVÍL, P. et al. (2009). The Effect of Silicon on the Structure of Fe-40 at. \% Al Type Alloys with High Contents of Carbon (1.93.8at.\%). In: Intermetallics, Vol. 17, pp. 39 - 45

[8] DOBEŠ, F. et al. (2011). The Effect of Carbon and Silicon Additions on the Creep Properties of Fe-40 at. \% Al Type Alloys at Elevated Temperatures. In: Intermetallics, Vol. 19, pp. 1526 1532

[9] KRATOCHVÍL, P. et al. (2008). The history of the search and use of heat resistant Pyroferal (c) alloys based on FeAl. In: Intermetallics, Vol. 16, No. 4, pp. 587 - 591

[10] NOVÁ, K., NOVÁK, P., PRŮŠA, F., KOPEČEK, J., ČECH, J. (2018). Synthesis of Intermetallics in Fe-Al-Si System by Mechanical Alloying. In: Metals, Vol. 9, pp. 20

[11] NOVÁK, P., VANKA, T., NOVÁ, K., STOULIL, J., PRŮŠA, F., KOPEČEK J., HAUŠILD, P., LAUFEK, F. (2019). Structure and Properties of Fe-Al-Si Alloy Prepared by Mechanical Alloying. In: Materials, Vol. 12, pp. 2463 
[12] NOVÁ, K., NOVÁK, P., VANKA, T., PRŮŠA, F. (2018). The Effect of Production Process on Properties of FeAl20Si20. In: Manufacturing Technology, Vol. 18, No. 2, pp. 295 - 298

[13] NOVÁK, P., NOVÁ, K. (2019). Oxidation Behavior of $\mathrm{Fe}-\mathrm{Al}, \mathrm{Fe}-\mathrm{Si}$ and $\mathrm{Fe}-\mathrm{Al}-\mathrm{Si}$ Intermetallics. In: Materials, Vol. 12, pp. 1748

[14] NOVÁK, P., NOVÁ, K., VANKA, T., PRŮŠA, F. (2018). High-temperature Behaviour of New Fe-Al-Si Alloy Produced by Powder Metallurgy. In: Manufacturing Technology, Vol. 18, No. 2, pp. 299 - 302

[15] LIU, I. C., SOMMER, F., MITTEMEIJER, E. J. (2004). Calibration of the differential dilatometric measurement signal upon heating and cooling thermal expansion of pure iron. In: Thermochemica Acta, Vol. 413, pp. 215 - 225

[16] ŠVEC, M., HANUS, P., VODIČKOVÁ, V. (2013). Coefficient Thermal Expansion of $\mathrm{Fe} 3 \mathrm{Al}$ and $\mathrm{FeAl}$ - type iron aluminides. In: $\mathrm{Ma}$ nufacturing Technology, Vol. 13, No. 3, pp. 399 404

[17] ŠVEC, M., VODIČKOVÁ, V., HANUS, P. (2014). The effect of phase composition and distribution on coefficient thermal expansion of Fe $3 \mathrm{Al}$ based iron aluminides. In: Metal Conference, pp. $1387-1392$

[18] VODIČKOVÁ, V., HANUS, P. (2015). The effect of zirconium and carbon addition on thermal expansion of $\mathrm{Fe} 3 \mathrm{Al}$ - based iron aluminides. In: Manufacturing Technology, Vol. 15, No. 4, pp. $739-743$

[19] ŠVEC, M., KEJZLAR, P. (2015). The Influence of Heat Treatment on the Phase Composition and Coefficient of Thermal Expansion of $\mathrm{Fe} 3 \mathrm{Al}$ - type Alloy with Niobium Addition. In: Manufacturing Tecbnology, Vol. 15, No. 4, pp. 705 $-710$

[20] ŠVEC, M., VODIČKOVÁ, V., KELLER, V., HANUS, P. (2018). The effect of chromium addition and heat treatment on phase composition of cast FeAlSi alloys. In: Manufacturing Technology, Vol. 18, No. 6, pp. 1029 - 1033

[21] ŠVEC, M., VODIČKOVÁ, V., HANUS, P. et al. (2021). Effect of Higher Silicon Content and Heat Treatment on Structure Evolution and High-Temperature Behaviour of Fe-28Al-15Si2Mo Alloy. In: Materials [online], Vol. 14, 3031 